\title{
1. Fiscal decentralization 101
}

Fiscal decentralization is in vogue. Both in the industrialized and the developing world, nations are turning to devolution to improve the performance of their public sectors. (Oates, 1999, p. 1120)

This book is about fiscal decentralization and subnational government finance in low- and middle-income countries. Getting decentralization right matters. Many countries are already decentralized and not completely satisfied with the results. Many others are exploring at least the outer edges of these murky waters because urbanization is giving rise to important questions about how best to provide the public services needed by more concentrated populations and how best to finance these services. People everywhere seem to be looking for ways to have more involvement in their governance. Ensuring that provincial and local governments play a greater role in providing services resolves these issues to some extent. But there is a significant gap between what theory suggests is best practice and the fiscal decentralization found in most developing countries.

Much of this book is our attempt to answer some key questions that inevitably come up in countries considering or attempting some form of fiscal decentralization. Many good studies of the success or lack of success of fiscal decentralization in various guises and forms already exist. ${ }^{1}$ Most such studies, however, focus on evaluating experience against a specific conceptual framework - a framework that seldom pays sufficient attention to the critical role played by the invariably context-specific and path-dependent ways in which fiscal institutions and administration, implementation strategies and political considerations come together.

Perhaps the most important lesson one can learn from examining the practice of decentralization in developing countries is that there is no one best way to get it right. This is because 'getting it right' means designing a program that not only matches the diverse objectives of fiscal decentralization, which differ from country to country, but that can also be implemented in the specific and diverse (and usually changing and uncertain) conditions that exist at different times in different countries. On the other hand, experience shows that there are many ways to get decentralization wrong. What is often thought to be best international practice may turn out to be wrong for a specific country. Studying the anatomy of 
decentralization failure can help us distinguish between theoretically bad (or at least seldom recommended) practices that may have been essential for some country to achieve its desired level and form of decentralization, and bad practices that are almost certain to make things worse in almost any circumstances. Similarly, studying successful decentralization experiences - cases in which countries have overcome different obstacles and succeeded in implementing some demonstrably successful type of decentralization - may provide useful lessons to others about how best to cope with their own problems.

Since fiscal decentralization means different things to different people, we begin this chapter by setting out the basic definition we employ throughout this book. In the remainder of this introductory chapter, we discuss why countries decentralize - the main rationales offered for decentralization in both theory and practice and the main benefits and costs usually raised in discussing decentralization policy. We provide a brief introductory sketch - Fiscal Decentralization 101, as it were - of the arguments we set out in detail in this book. We turn in the next chapter to a review of what the existing empirical literature tells us about these matters.

\section{DEFINING FISCAL DECENTRALIZATION}

In this book we understand decentralization in its ideal form as the empowerment of local populations by the empowerment of their elected local governments. ${ }^{2}$ The fiscal aspect of decentralization, which we refer to generally as fiscal decentralization, requires the central government to give subnational governments some power to make spending and financing decisions. $^{3}$ Decentralization in this sense is often called political decentralization or devolution because decisions that would otherwise be made at the central level are devolved to some or all levels of government below the center: to the regional level (states or provinces); the local level (cities, towns, municipalities, or districts); and sometimes even to a fourth level (for example, districts within a city, rural villages). ${ }^{4}$ Unless fiscal empowerment (in terms of the right to make decisions about taxing and spending) is matched by political empowerment (so that these decisions are made by elected officials responsible to local citizens), theory, empirical studies and experience all suggest that devolution may not necessarily lead to good results. ${ }^{5}$ This is especially true when, as is not uncommon, more spending power than taxing power has been devolved.

Fiscal decentralization is not simply fiscal devolution, but it is far more than the deconcentration of decision-making and service-delivery powers to regional or district offices of the central government. Administrative 
decentralization along these lines may make good sense when it comes to managing the delivery of central government services. Decentralization of decisions about such matters as the choice or design of infrastructure projects, for example, may properly be the responsibility of the provincial or district level office of a central government ministry in order to be sensitive to needs and demands particular to a region. Heads of schools or hospitals may similarly be charged with allocating the resources made available to them, generally subject to supervision from above with respect to both the honesty of their accounts and the results of their activities. In some instances, elected local government officials may be invited to the discussion as part of a planning committee or in some other capacity; but the deciding voice clearly remains that of the higher-level government that provides the funds supporting the activities in question.

Although the dividing line between decentralization and deconcentration is clear in principle, the two approaches to service delivery are often not independent of one another in practice. Deconcentration does not empower the local population in any direct way; but sometimes, as in Indonesia in 2001 - when over 2 million central government employees were absorbed by local governments with no major disruption in service delivery - it was an important prerequisite to implementing a successful fiscal decentralization (Directorate General of Fiscal Balance 2012). ${ }^{6}$ Moreover, since local residents receive public services not only from local government expenditures but also from central government spending in the local area, combining the two (although seldom easy to do) may, as DeLog and LPSI Secretariat (2015) demonstrates, provide a more accurate picture of public service expenditures in the local area.

Another form of decentralization often found is delegation, when a higher-level government contracts (implicitly or, less commonly, explicitly) with a lower-level government to deliver a particular service. ${ }^{7}$ This 'principal-agent' relationship allows the senior-level government (the principal) to retain all decision-making powers, with the junior-level government (the agent) delivering the service. Much has been written about the inherent incentive problems with such agency arrangements owing to the asymmetric information problems arising when, as is usually the case, the putative agent knows much more about what it does and how it does it than the principal ever can. Little information is available about the effects that different forms of intergovernmental arrangements along these lines may have on the efficiency, efficacy and equity with which services are delivered ${ }^{8}$ But there is no question that with delegation the main accountability for the service delivered is upward from the local government to the higher-level government. Because local governments usually have little or no discretion over the quantity or quality of the service or the way in 
which it is provided, there is little or no local government accountability to the local population, and hence no real local empowerment. The bifurcation of political and administrative responsibilities forces local agents to be accountable downward to those to whom they provide services and upward to those who pay for the services they provide. Since he who pays the piper picks the tune, it is not surprising that such dual accountability seldom ends well for those at the bottom of the system.

Another type of decentralization not included in our definition of fiscal decentralization is community-driven development (CDD), that is, the delegation of service delivery powers to community-interest groups. Although these community groups become parallel local governments to some extent, those who run such organizations are usually not elected and not explicitly accountable to the local population. The community-driven approach may enhance the probability of successful decentralization by providing a more effective lobby voice for local interest groups. It may help prevent elite capture - though in some instances it may itself be captured (perhaps by a different elite). It may sometimes be an effective way to deliver local public services, and may give a more effective voice to heretofore disenfranchised groups. These are all good things. But CDD is decidedly not a substitute for a representative local government, and may even crowd out traditional local governments (World Bank Independent Evaluation Group, 2008).

On the other hand, some gray areas of fiscal decentralization are deliberately included in our discussion. Even when local governments are not elected their centrally appointed political leadership may act at least to some extent in the local interest. In China, for example, the central government rewards the successes of the provincial and local officials they appoint, and encourages them to compete with one another (Bahl and Martinez-Vazquez, 2006). Some have hailed such competition as a 'market-preserving approach' that has been an important factor in China's development (Qian and Weingast, 1997). However, the Chinese system falls far short of one driven by local preferences, and has been criticized precisely because of the limited concern that many local officials have shown about local public services compared to their need to fulfill the wishes of the central authorities by focusing heavily on economic growth (Bahl et al., 2014; World Bank and Development Research Center of PRC, 2014). Accountability is mainly upward to the center and not downward to local residents.

A second gray area relates to the very limited effective budgetary discretion that many local governments have, owing to limits imposed on their revenue powers and the unfunded expenditure mandates imposed on them by central governments. ${ }^{9}$ In some countries, even large elected subnational 
governments end up as little more than spending agents of higher-level governments. In Colombia, for example, although most expenditures for health and education appear in the budgets of the elected regional governments (departamentos), this is more a matter of delegation than devolution; most decision-making remains at the national level (Acosta and Bird, 2005). In Cambodia, local governments have no formal expenditure responsibilities, though they may undertake 'permissive' expenditures (Smoke and Morrison, 2011). Nonetheless, even in these cases local governments have some discretion and are to some degree accountable to the local population who elects them. Moreover, in many countries local governments could have more autonomy if they chose to do so. ${ }^{10}$ These 'mixed' cases are considered to some extent in this book because their experience may contain some important lessons about how low- and middle-income countries may perhaps transition more easily to full fiscal decentralization, as well as about the possible costs and benefits of such a transition.

\section{WHY COUNTRIES DECENTRALIZE}

Real decentralization in the sense just defined is not easily achieved. It requires one level of government - usually the center - to give up some power to its 'subordinate' regional and local levels. Doing so is not likely to delight the hearts of those charged with carrying it out. Nonetheless, as mentioned earlier, a surprising number of developing countries are decentralized to some extent, though often more in form than reality. Some may have been created that way by their former colonial authorities or may have emerged from the fires of civil war or national struggle. Some may have been forced to follow this path to resolve political differences between regions or groups. Still others may have chosen to decentralize for a variety of administrative, technical and economic reasons.

For whatever reason, many developing countries have in recent years decentralized government activities to some extent - often for reasons not explicitly spelled out - and with varying degrees of success. Some countries have invested considerable time, resources and political capital in designing and implementing their decentralization programs: establishing new secretariats or departments to initiate and guide the process; putting into place a legal foundation for local governments; redefining a host of fiscal institutions ranging from taxes to borrowing to expenditure management; and sometimes incurring heavy transition costs. Donors also have invested heavily in fiscal decentralization. Between 1990 and 2006, for example, the World Bank provided some form of lending and non-lending support 
to 89 countries for decentralization initiatives, devoting about 8 percent of its resources (over $\$ 30$ billion) to such efforts (World Bank Independent Evaluation Group, 2008). ${ }^{11}$

One reason so many countries and donors have been attracted to fiscal decentralization as a potential way to contribute to economic and political development is because it is not difficult to tell a wonderful story that can be sold by political leaders to various stakeholders. The story has to do with how people will become better citizens when they have more control over their public sector, and how the result will be better services, better governance, faster and more balanced economic development, and even nation-building. Of course, since circumstances differ widely from country to country (and from time to time even within the same country), different wonderful stories have been told in different places at different times.

Russia's fiscal decentralization as originally structured seems to have been mainly designed to head off separatist movements (MartinezVazquez et al., 2008). ${ }^{12}$ On the other hand, South Africa's devolution of some decision-making power to a new set of provincial governments as well as to over 800 local level governments was arguably just the sort of empowerment one would expect in the aftermath of apartheid (Bahl and Smoke, 2003). However, as decentralization progressed, and especially as the political situation changed, both countries subsequently moved back in different degrees to more centralized structures. In contrast, when it reformed its constitution in 1988 after a highly unpopular centralization under the previous military dictatorship, Brazil went much further than either Russia or South Africa towards a sustainable decentralization. Despite many attempts to revise intergovernmental fiscal arrangements in recent years, the extent to which decentralization was enshrined in the Brazilian constitution and the way in which the political balance shifted has made it almost impossible to reverse the direction to any significant extent (Bird, 2012; Wetzel, 2013).

Many claims have been made in the literature and in political discussions in many countries about such possible economic gains from decentralization as a faster rate of economic growth, greater public sector efficiency, improved service delivery, and greater democracy and nation-building. Opponents of decentralization often doubt the extent to which such good things result from decentralizing government activities, and assert that such bad outcomes as weaker stabilization policy and increased inequity, corruption and conflict are more likely. In the remainder of this chapter, we consider some of these arguments, and in the next chapter we examine the empirical evidence.

Countries decentralize to differing extents and in different ways for several reasons. The economic rationales commonly mentioned mainly 
draw from the theory of fiscal decentralization first set out in detail in Oates (1972). This theory stresses the potential gains in terms of economic efficiency. However, this notion, central to the economic case for decentralization, is seldom raised in political debates. Instead, debates about decentralization usually stress grander but vaguer gains such as increased economic growth and nation-building. ${ }^{13}$ Other possible gains often cited include greater accountability, improved service delivery and perhaps more and more effective revenue mobilization. Unfortunately, as Treisman (2007), Mascagni (2016) and Lago-Peñas et al. (2016) discuss in detail, there is little evidence to support definitive conclusions with respect to any of these matters. Indeed, the safest generalization about the outcomes of decentralization is that one cannot safely generalize. How outcomes are affected by any particular decentralization measure depends so heavily on the specifics of its design, how well it is implemented and the historical, institutional, political and economic context within which it is implemented that those who seek simple, clear answers are bound to be disappointed.

Nonetheless, in principle the basic efficiency argument for decentralizing public decisions - which is essentially the same as the case for market economics in general - is convincing. Decisions are best made when they are made by those in the best position to make them, which in most cases means those closest to the issue in question. Governments closer to the local or regional economy are thus presumably in a better position to facilitate economic development by deciding such matters as: the most appropriate regulatory environment for local business; the right infrastructure investments to make; the proper balance between taxation and user charges; and, in general, the fiscal environment best suited to support the local economy. The best choices are often those that are made locally. For some big cities, the main bottleneck to job growth might be traffic congestion, so the top priority may be investment in transportation infrastructure. For others, where heavy industry is important, the priority may be power and water. For those with significant in-migration from rural areas, it may be housing and slum control. Similarly, although those who do not live there may think that the biggest need in rural localities is for clean water or better education, many rural people and their local governments may be focused on more immediate needs and give priority to irrigation, electricity or farm-to-market roads (Fiszbein, 1997).

In principle, people are more likely to get the package of public services they want, if not necessarily what others think they should want, under a decentralized system than under a centralized system. One result of central government supervision of the budgetary affairs of every subnational government may thus be poor public service outcomes, particularly 
in large countries or those in which physical communications with the national capital are difficult. Consider the following anecdotal examples:

- In Russia, a country with 11 time zones, in the early 1990s the budgets of the 89 regional governments were approved and revised in Moscow, often after face-to-face negotiations (Martinez-Vazquez, 1994)..$^{14}$

- In Colombia some years ago a request by a city for permission to borrow funds to fix a road required 65 official signatures and numerous visits to the national capital to secure approval (Bird, 1970).

- In Indonesia in the 1980s changes in bus routes in Jakarta reportedly required approval by the President of the country.

- In Papua New Guinea, a country created with an elaborate set of decentralized provincial governments - essentially large rural municipalities - well-founded fears of the low level of administrative capacity at the local level led to the creation of a central ministry that was supposed to monitor and control provincial finances. The most observable result was a complex and ineffective dual layer of administration (Bird, 1983). ${ }^{15}$

- In mountainous Nepal, many of the 4,053 local governments are several days' journey from Kathmandu.

In none of these cases does it seem credible that a few officials in a central ministry are going to be able (or willing) to do the best job at the least cost for every community. Indeed, in some countries many officials charged with supervising particular localities had never visited them and knew nothing about them. ${ }^{16}$

Size matters. China and India have populations in excess of 1 billion: China has 58,545 subnational governments, ${ }^{17}$ while India has 237,$687 ;{ }^{18}$ Brazil has a land area in excess of 8.4 million sq. $\mathrm{km}$; and Indonesia is made up of more than 6,000 inhabited islands. Despite the centralization approach of Soviet-era government in Russia and most (not all) countries under Soviet influence until the late 1980s, most large countries have always had some form of decentralized governance. ${ }^{19}$ For example, although China has only one time zone for its vast territory, and is at least as controlled from the center in political terms as Russia, it has always been run in a much more decentralized fashion than Russia or most Central and Eastern European countries under Soviet influence (Wong and Bird, 2008). None of this is to say that small countries do not see advantages to fiscal decentralization. For example, Lao PDR (population 6 million) has been exploring decentralization options for a decade (Martinez-Vazquez et al., 2006a); Bhutan (population 0.8 million) included strengthened local 
governments in its vision for Gross National Happiness in its ninth fiveyear development plan; and several Caribbean countries have undertaken reviews of their local government structure (National Democratic Institute for International Affairs, 2004).

As noted above, in countries big and small the economic argument for fiscal decentralization is straightforward (Oates, 1972). Assume that people's preferences for government services vary for whatever reason religion, language, ethnic mix, climate, income level, economic base. Assume further that to a considerable extent people have either sorted or adapted themselves so that those who live in the same neighborhood or region have broadly similar preferences for public services. If governments respond to these preferences, decentralizing public sector decisions to subnational governments will result in variations in the package of services delivered in different regions. People in each region will get more of what they want and less of what they do not want; and (in the absence of externalities) everybody will be better off - or, as economists put it, national welfare will be enhanced. A more centralized system with more uniform service provision would make people worse off, since even if they could move elsewhere to get the services they want, they would incur additional costs to do so.

When the preferences of local people become more influential in affecting local government decisions, two important results ensue. First, in a democratic setting - and to some extent (as Chinese experience suggests) even when there are no local elections but politicians are for whatever reason sensitive to public sentiments - local officials become more responsive to the local population served for the quantity, quality and variety of services provided. Second, because people are more likely to get what they want, they are also likely to be more willing to pay for local services.

Successful fiscal decentralization may thus, in principle, simultaneously resolve several common problems facing developing countries: increased revenue mobilization; improved accountability of elected officials; and more grassroots participation in governance. It may also, as Lewis (1967) noted long ago, lead to more learning and increased capacity development at the local level, thus weakening a constraint often said to make decentralization unfeasible. Some have argued that decentralization will also create incentives - essentially by 'crowd-sourcing' to more minds the task of how to deliver services within a budget constraint - that will increase innovation in decision-making about local public services (Oates, 1999). Since in most developing countries almost everyone can easily identify public services that can and should be better provided (that is, provided more in accordance with their preferences) this story is such a good one 
that it is easy to believe that important welfare gains may result from decentralization even if they cannot be precisely measured. ${ }^{20}$

As we discuss in the next chapter, measurement is essential to good policy because decentralization may not be worthwhile unless the gains are sufficiently large to offset its costs. But even if the possible efficiency gains from fiscal decentralization are demonstrably important they may not be captured by subnational governments unless a substantial number of institutional conditions are in place. Ideally, for example, there should be an electoral system that gives an effective voice to the local population. There should also be a capable local administration reporting to a local council which has both significant expenditure responsibilities and significant local taxing powers and operates within the kind of well-designed and effectively implemented intergovernmental institutional structure we discuss in later chapters. In most middle- and low-income countries, few if any of these conditions are in place - and even if they are, success is not guaranteed. The political system may go astray. External crises may dominate the policy agenda. The local population may be too impatient to ride out the problems of the transition period. The central government may hinder rather than help subnational governments as they try to capture these efficiency benefits. Good stories do not necessarily lead to good policies.

\section{Democracy and Accountability}

The increased interest in fiscal decentralization since the mid-1980s has roughly coincided with a growth in democracy around the world. In some countries, democratic governance evolved over time with economic development and the development of competitive political parties (Mexico, Brazil). In others, authoritarian regimes were replaced by elected governments, with voters assuming more power and responsibility (Philippines, Indonesia). When fiscal decentralization has accompanied subnational elections, as in Colombia, it has become an important component of the democratic system. In 1980, fewer than half the countries in Latin America were classified as democracies, and in only three were mayors elected (Hausmann, 1998). In contrast, in 2010, mayors were elected directly by local citizens in every country in the region except Cuba and Guyana. ${ }^{21}$

Of course, the mere existence of elections does not necessarily mean strong local governments, as countries like Cambodia and South Africa show. In the so-called transition countries (mainly in Central and Eastern Europe), for instance, Kravchuk (2008) found only nine out of 29 in which local elections were critical to ensuring government accountability. Still, political decentralization appears to increase both local involvement and 
official responsiveness to local interests, and to lead to greater demands for fiscal decentralization (Ebel and Yilmaz, 2003; Manor, 1999).

There are many problems in ensuring adequate accountability at the subnational level. Imperfect as the process is, open elections remain the best way we have to ensure that subnational politicians are accountable to the local population. ${ }^{22}$ Since such elections, especially at the local and regional level, are not the norm in much of the world - for example there are none in countries as important as China and Egypt - in practice, accountability usually rests on the extent to which local political leaders see their self-interest as being related to the satisfaction of the local population. Even then, what they do in terms of providing services is often more likely to reflect the wishes of the higher-level governments that appoint them than the preferences of the local population. In China, for example, the reward system for officials has long been heavily weighted toward economic development (Bahl et al., 2014). Different provinces take different approaches to economic development, so there is competition for jobs and investment; and perhaps, as Qian and Weingast (1997) have argued, the results may encourage growth. But no one knows, or asks, whether local people might perhaps prefer more in the way of social services. ${ }^{23}$

Even with full and free elections, accountability to local voters is of course not guaranteed. People may not have the information or inclination to push for more accountability. Elite capture may result in local governments being effectively accountable only to the agenda of a small group which may or may not map into local preferences (Bardhan and Mookherjee, 2000). Or local service delivery may be hostage to the rule-making and control goals of central ministries or their local representatives. The electoral process itself may be an impediment. For instance, elected leaders may be more accountable to the national party than to the local population. Strong party discipline may perhaps improve the quality of local governance; but whether better governance means a better match with local preferences varies from place to place (Hankla and Downs, 2010)..$^{24}$

Many of these constraints on downward accountability could be relaxed (Yilmaz et al., 2010). Institutional measures such as term limits, recall, local council oversight and requiring local council independence exist in some countries and may do some good. For example, term limits may protect against the capture of the local council by elites; on the other hand, they may also lead to discarding the important learning of incumbents. Recall and other 'direct democracy' devices (such as voting on specific issues) may curb abuses of power, but they may also intensify group conflicts or lead to fragmented and inconsistent policy outcomes. Some countries, such as Brazil, have introduced other 'social' accountability measures such 
as public meetings, referenda and special citizen oversight groups, although again with mixed success. ${ }^{25}$

Accountability is also shaped by the way in which local government administration is structured. The structure most conducive to accountable decentralization is one in which the chief officers of the local government are accountable to their elected local body, and the local government controls employee pay rates and has the authority and responsibility to hire, promote and fire as well as to manage and evaluate employee performance (Sud and Yilmaz, 2013). Often, however (as in India), local chief administrators are appointed and rewarded by a higher level of government, so their primary allegiance is likely to be to those who control their careers. Even when employees are nominally under local government control they may, like teachers in some countries in Latin America, be more responsive to their unions and to the higher-level governments that establish their salaries and provide most of the funding. In Peru, for example, although regional governments have significant responsibility for health, education and transport expenditure, the central government imposes such strict expenditure mandates that the result is closer to deconcentration than real decentralization (Martinez-Vazquez, 2013).

Many observers have noted that local governments in some countries often seem unwilling to exercise even those powers that they have. Critics have often focused on the poor performance of local governments as the principal explanation for failures in decentralization such as poor service delivery. Sometimes such criticisms are legitimate. Extended dependence on central charity is as likely to breed passivity and dependence in governments as in people. Indeed, sometimes local governments are too passive. As Breton (2004, p. 37) notes, local governments "cannot be empowered by others ... If they are to become empowered, they must empower themselves." This vision, that the upraised local fist must replace the outstretched local hand for decentralization to succeed, may be a bit extreme. Around the world some cities, regions and localities thrive in the same setting where others fail, so success to some extent likely follows initiatives from below rather than flowing effortlessly and evenly to all as bounty bestowed from above. Often, however, the basic problem is not so much that local governments are incapable of doing or unwilling to do more or better, but that the institutional structure within which they function - a structure essentially established by higher-level governments creates incentives to make decisions that are subsequently viewed by some as bad. Central governments largely get the local governments they want, and deserve.

What we conclude from all this is that the necessary conditions for successful fiscal decentralization usually include strong central government 
commitment to the objective, and strong central leadership and support in providing adequate resources and in managing the inevitable conflicts that emerge in any decentralization process. Prud'homme (1996, p. 357) may have overstated the case when he said that "where decentralization is needed (because central governments are corrupt and inefficient), it cannot be implemented. Where it can be implemented, it is not needed." But he was basically right in stressing the central role of the central government in determining both whether and how effectively decentralization occurs in any country. We develop this theme in detail in later chapters.

\section{Service Delivery}

The argument that fiscal decentralization will improve public service delivery usually falls on receptive ears. The level and quality of services provided through more centralized systems in developing countries is often poor. Intuitively, it seems credible that more local control over expenditure decisions would make things better. Local governments are presumably better positioned to determine the right location for public facilities and to recognize local service needs and control the performance of local employees. In addition, if they are accountable downward for their actions they may have more of a vested interest in better local public services than do higher level governments, and therefore be more responsive to their constituents.

For local residents to care enough about the quality of local services to hold elected officials accountable, however, the government may need to be responsible for important services such as, say, public utilities and primary education. If local governments are responsible for little more than such housekeeping functions as the maintenance of local parks and public buildings, people are unlikely be overly concerned about the quality of services delivered. They are much more likely to care if water is not clean, or even available, or if teachers do not bother to show up at the local school. When such highly visible results hit home, people are more likely to turn out at town hall meetings and elections, to refuse to pay for the services, and to protest visibly against service failure. ${ }^{26}$ Even China with its appointed local governments has a long history of such local protests at service failures. In response, although higher-level authorities have sometimes simply suppressed such dissent they have at other times reacted by replacing unpopular local officials and demanding changes in local policies. ${ }^{27}$

In some developing countries, especially federal countries, important functions are assigned to subnational governments, mainly those at the regional level. In many countries local governments do not have functions 
that people consider significant to the quality of their lives. In Brazil, for example, state governments account for 26 percent of total taxation, while local governments account for only 6 percent of taxation. In India, although state governments account for 37 percent of taxation, local governments collect almost no taxes. ${ }^{28}$ In some unitary countries - Philippines, Indonesia and Colombia, for example - locally provided services are important; but in many others, such as Egypt, they are not. There are often accountability problems when the assignment of functional responsibility for services such as primary education to the regional or metropolitan area is too far removed from the local populations served.

As we discuss in Chapter 5, the efficiency gains from decentralized service delivery are best captured when beneficiaries pay for the government services that they receive. For this to occur, subnational governments must be empowered to determine at least some tax rates and user charges. If subnational governments have such taxing power, local demands for accountability are likely to be stronger than if services are financed primarily by a transfer from the center. This accountability argument for subnational government taxation works best when there is equivalent accountability on the expenditure side. If expenditures are delivered under a delegation approach - where central line ministries make many or most decisions about who gets what in terms of service delivery (as is largely true at the regional level in Colombia, for example) - the case for independent local taxing powers is weakened (Acosta and Bird, 2005). It is hard to hold local governments accountable for the quality of services when they have little discretion over what they provide. The effective local accountability underlying the case for fiscal decentralization usually depends on highly specific local conditions that establish, influence and shape the degree to which different local groups are willing to and capable of playing a real role in local decision-making.

\section{Revenue Mobilization}

Another potential gain from fiscal decentralization may be an increase in the overall rate of revenue mobilization, reflecting the presumably greater willingness to pay for services more in tune with local preferences and perhaps also the potential comparative advantage of subnational governments in collecting certain taxes. Although the amounts involved may not be large, the potential revenue gain from decentralized taxation may nonetheless be significant for developing countries in which the average ratio of tax to GDP has been stuck at about 16 percent for three decades, with only about 11 percent of this amount being raised by subnational governments (Bahl and Bird 2008; Bahl, 2014, IMF, 2011). ${ }^{29}$ 
Two questions may be asked about the possibility of raising more revenue from a more decentralized system. First, are central governments willing to allow local governments to impose and collect new revenues? Second, are local governments willing to take on the difficult political task of doing so? Higher-level governments may fear that increased regional and local government tax collections can be achieved only if the central government loses some of its own 'tax room' - for example, because taxpayers are willing to accept only a certain amount of tax burden on any one base ${ }^{30}$ Or they may think that it is cheaper and more efficient for the central government to levy taxes and to finance subnational governments with transfers than for such governments to levy their own taxes. ${ }^{31}$ Of course, all governments are usually happier to spend 'other people's money' in the form of transfers than to try to extract increased revenues from their constituents.

\section{Nation-Building}

Some countries appear to have moved in the direction of decentralization in order to achieve political stability. Chechnya, East Timor, Kosovo, Kashmir, South Sudan, Rwanda, Burundi ... the list of territorially based ethnic groups that have taken up arms to varying degrees against the state is lengthening. Nor, as the cases of Scotland, Catalonia, Flanders and Quebec show, are such pressures confined either to lowincome countries or to outright civil war. It is not surprising that some countries have tried to pre-empt separatist pressures by decentralizing some activities.

As World Bank (2000, pp. 107-8) puts it: "When a country finds itself deeply divided, especially along geographic or ethnic lines, decentralization provides an institutional mechanism for bringing opposition groups into a formal, rule-bound bargaining process." This study went on to offer five specific political rationales for decentralization:

1. Decentralization may sometimes serve as a "path to national unity." Two examples often cited are South Africa (Bahl and Smoke, 2003) and Uganda (Smoke et al., 2010). Of course, much has since happened in both countries.

2. Decentralization may in some instances "offer a potential political solution" to a civil war. Sri Lanka is a case in point, although decentralization has been less prominent on the political agenda since the central government defeated the insurgent Tamil north in 2009. The extent to which the peace might best be sustained by more effective decentralization continues to be a contested issue in Sri Lanka. ${ }^{32}$ 
3. Less drastically, decentralization may serve as "an instrument for deflating secessionist tendencies." The examples often mentioned are Ethiopia and Bosnia and Herzegovina. The case of Bosnia is discussed in detail by Fox and Wallich (2007) and Ethiopia in Yilmaz and Venugopal (2011) and Prichard (2015).

4. Decentralization may attempt to achieve a similar aim by "conceding enough power to regional interests to forestall their departure from the republic." The Russian Federation is an example (Treisman, 1999), though the course has been sharply reversed in this century as power has been reconsolidated at the center.

5. And, finally, the report suggested that decentralization may be used to co-opt "grassroots support" for central policies. World Bank (2000) cites Colombia as a relevant example, though for a quite different take on the Colombian case see Bird and Fiszbein (1998). A more appropriate example might be Bolivia, where a 'municipalization' program was adopted in the early 1990s, in part precisely to strengthen the national state by positioning it as the main lifeline of local development while at the same time countering the centrifugal tendencies that a more 'federal' decentralization program, focusing on the provincial level, would have fostered (Grindle and Domingo, 2003). For a fuller account of the Bolivian experiment, which succeeded at least for a time in making government more responsive to local wishes and needs, see Faguet and Pöschl (2015).

Whether or not national unity is enhanced by fiscal decentralization is a complex, interesting and largely unanswered question. ${ }^{33}$ One reason it may be enhanced is because at root decentralization is all about citizen participation in government. How well the public sector works, and in particular the extent to which people have to pay for what they get and expect to get what they pay for, may be critical to establishing the kind of state legitimacy and state-society relations that constitute 'state-building. ${ }^{34}$ Many people in developing countries feel estranged from their governments: perhaps because they have been ignored for so long that they simply do not trust the government; perhaps because they feel that their voice is too small to count; perhaps because there is either no democracy or because, if there is, they have not yet learned to use it effectively. Whatever the reason, few participate in government decisions by voting or joining the debate about public policy in any way, sometimes because of fear of the consequences if the authorities do not like what they say. ${ }^{35}$ When people feel that they have little influence on governance, they may be content as long as their private well-being is improving, but they are unlikely to become actively involved in the process of governance. If one result of decentralization is 
more participation by more people in the governance process, the outcome may be, in at least some cases, more identification with both the local and the national governments. ${ }^{36}$

Another way in which decentralization promotes national unity may be by incorporating disaffected groups more effectively in the national framework. Those who live in different regions of the country, or even different neighborhoods in the same city, may want different things from their governments, especially if they constitute a relatively homogeneous group that differs in some way from others in the country or city. Such groups may not only want to be able to choose for themselves a package of services that best fits their demands and to deliver these services themselves; they may also wish to establish in some formal way their separate (usually ethnic) identity. Recent examples include the campaigns for regional autonomy in the largely Muslim Mindanao province in the Philippines as well as in Aceh province in Indonesia. The pressure for ethnic regions may become even stronger when control of natural resource wealth is at stake, as the case of Nigeria has long demonstrated.

Of course, such regional or localized group pressures are not limited to countries that are ethnically diverse. Diversity in citizen preferences between urban and rural areas and in regions with different economic bases leads to some pressure for devolution of budgetary powers everywhere. Centralized systems, even if some service provision is deconcentrated or delegated, usually provide more regionally uniform service levels than more decentralized (devolved) systems, and many - perhaps most - people may consider this to be a desirable outcome. Others, however, may prefer more room for regional and local choice. On the other hand, in some cases, central governments may intentionally favor some regions over others, either to keep potentially troublesome regions calm or for reasons of national security (for example, in border regions). Sometimes they may achieve such differential results even if they do not do so intentionally, for example, by setting strict rules about not only what is done but also how it is done throughout the country to control input costs even though the result may be to produce different levels of service output in different regions. In general, however, when decisions are made centrally rather than locally there is less diversity in service levels across the country.

One consequence of decentralization in such a system is almost always increased inequality when more decisions are made locally, as quickly became evident in much of central and eastern Europe with the breakup of the old Soviet bloc (Bird et al., 1995; Bahl, 1994). Similar issues often arise in the many developing countries which emerged from the colonial era with artificial boundaries and have since contained (and often restrained) ethnic divides within those boundaries. The result in some countries has 
been civil wars (Nigeria, Syria) and continuing unrest and threats of secession (Turkey, Myanmar). One approach to controlling such problems has been 'fiscal appeasement' (Treisman, 1999) - the buying off of dissent in part by special concessions to local autonomy. Developed countries like Belgium, Canada, Spain and the UK have all trodden this path to some extent in recent decades. ${ }^{37}$ Sometimes such policies have also been followed in developing countries like Nigeria (after the civil war of the 1960s and the later unrest in the oil-rich south and the Muslim north) and Indonesia (particularly after Aceh and Irian Jaya threatened to follow the lead of East Timor and opt for independence). Similarly, Muslim Mindanao was given special standing as an autonomous region and some fiscal concessions in the Philippines (Wallich et al., 2007; Manasan, 2009). Even Russia, in addition to prolonged armed struggles with Muslim Chechens and others in the Caucasus region in the early 1990s, negotiated special treaties with disaffected regions that were rich in natural resources. ${ }^{38}$

Changing labels and paying money does not always work, however. Sometimes, national politicians pull back from making accommodations to ethnic regions because it makes it more difficult to build a governing coalition (Eaton et al., 2010). Sometimes, they do so in the belief that increased fiscal transfers might be used to finance insurgents. ${ }^{39}$ And sometimes, no matter what is done, countries fall apart, as happened in Czechoslovakia, Yugoslavia and the former Soviet Union as well as in Indonesia (East Timor) and Sudan (South Sudan) - and may well happen again in such other 'failed states' as Somalia and Libya.

On the other hand, in Vietnam, Germany and Hong Kong reunification gave the 'new' regions special arrangements, including some autonomy or special financial treatment within the intergovernmental fiscal system. As noted above, however, such arrangements are sometimes criticized as harming rather than helping national unity. More autonomous decentralized governance may offer regional politicians the opportunity to develop a following, and hence potentially threaten the hegemony of the central government. Mexican history provides several instances of such regional revolts (Cline, 1962), which is one reason why Mexico remains wary of giving too much power to elected provincial governors. For similar reasons, federalism is an unpopular concept in Indonesia.

The political impact of decentralization is thus far from clear in practice. Neither empirical research nor country case studies demonstrate that decentralization, asymmetric or not, is always likely to promote national unity (Vaillancourt and Bird, 2016). The available empirical evidence is thin and provides little support for the conjecture that decentralization avoids the breakup of nations (Lago-Peñas et al., 2016.) Perhaps the best recent appraisal of this complex issue is that of Sorens (2015), who 
concludes that fear of secessionist pressure is perhaps the main reason that so many developing countries have proved so reluctant to heed the arguments of economists (like us) who have urged the importance of decentralizing taxation power. Faced with what they see as a choice between getting decentralization right and keeping their often fragile countries together, most politicians - perhaps even most people - seem more willing to forgo some potential economic gains than to risk losing their country.

All any honest advisor can perhaps do when decision-makers are unwilling for political reasons to do what seems needed to achieve the full economic benefits of decentralization is to be sure that the consequences of the decision are clearly understood. Throughout this book, for example, we stress the importance of decentralizing adequate tax power if decentralization is to work properly. This message has been hard to sell to national politicians and officials. The damage arising from the absence of this key link in the decentralization logic may be alleviated to some degree, as we discuss later, by introducing various small adjustments in the intergovernmental fiscal system. However, the interlocking marginal institutional alterations required are usually difficult to explain to those who demand a simple answer even when none exists. The diverse and complex reality of intergovernmental finance seldom permits achieving equally good results when the best solution is ruled out.

A good understanding of the basic theory is essential. But even the best theory can only tell us the questions that must be answered, and not how to get the best results possible in any particular context. Designing and implementing a good fiscal decentralization system demands painstaking investigation and consideration of the specific context in question. To produce a clear answer, theory must often assume that a wide array of conditions hold which may not always be true for the case at hand. Without economics, however, we would have no sound framework within which to understand how the many forces at play in determining outcomes interact, let alone how to assess and evaluate the weight that must be attached to each given our policy aims. In this book, we try to set out the key elements of the analytical framework in a way that might help outsiders to understand and insiders to improve how decentralization may best work in any particular case. But we do not pretend to determine what any country should do, let alone guess what it might do.

One lesson that emerges from our discussion is that different combinations of objectives and problems in different settings call for different solutions. As Litvack et al. (1998) said some years ago, if countries suffer from a whole range of problems - weak democratic institutions and processes, weak legal and regulatory systems, highly imperfect markets for land, labor and capital, poor information, weak financial systems, and 
nontransparent fiscal systems - probably the most they can or should attempt is very modest decentralization of a few clearly local services. If things are not quite that bad, it may perhaps be possible to construct feasible approaches to resolving each of the problems just mentioned, but none of the possible solutions are likely to be simple, most of them are long-term, and some may require fundamental (and difficult) changes in political institutions. In such cases, it is important not to claim that any specific reform, even one in the right direction, will yield the full benefits of fiscal decentralization.

Anyone who thinks that it is simple to design and implement a fiscal decentralization program without substantial preparation and sustained effort needs to think again. The various costs and obstacles discussed in the next section can be overcome in principle, as we demonstrate later in this book. But it is of course much harder to do something well in practice than to stand above the fray and prescribe what others should do. Still, we think that many of the pitfalls and roadblocks that countries have encountered in their attempts to decentralize are less a reflection of the inherent problems with decentralization than of inadequate preparation. All too often, countries (and their advisers, outsiders and insiders alike) have placed undue reliance on the veracity of unproven generalizations about what is good and necessary for success. When coupled with the usually overoptimistic expectations about the extent and rapidity with which the expected gains will be realized - necessary though such hyperbole may seem for political acceptance - failure is all too often inevitable.

\section{THE COSTS OF FISCAL DECENTRALIZATION}

In most low-income countries, the fiscal system is highly centralized with, on average, about 80 percent of government expenditures made by central governments. There are advantages to a centralized fiscal system and there are costs associated with fiscal decentralization. Several wellknown papers have focused on these costs and raised concerns about the "dangers of decentralization" (Prud'homme, 1995; Tanzi, 1996), although many of the arguments put forth were soon vigorously debated (McLure, 1995; Sewell, 1996; Spahn, 1997). We discuss here the principal disadvantages often associated with decentralization, including economies of scale, failure to deal adequately with externalities, lack of local capacity, stabilization concerns and corruption. While there are some risks on all these fronts, it turns out that most of the economic dangers attached to decentralization can be ameliorated - if not eliminated - by careful design and implementation. 


\section{Stabilization Policy ${ }^{40}$}

Most economists agree that macroeconomic stabilization policy is an issue best left in the hands of the central government (Musgrave, 1959). Fiscal decentralization makes the design and implementation of central stabilization policy more complex because it adds a layer of government actions that are not fully controlled by the center but that must be taken into account. Regional and local governments may in various ways make it more difficult for the central government to implement potentially important stabilization policies such as raising taxes or reducing public spending. Such constraints matter because many low- and middle-income countries encounter macroeconomic difficulties as a result of their vulnerability to commodity price fluctuations, crises of one sort or another arising from the international financial system, or simply poor management.

For example, almost every country in the world, no matter how well managed, is affected by worldwide crises like that in 2009-2010, which reduced tax revenues almost everywhere. In countries in which intergovernmental transfers are tied by formula to central tax collections - as is the case, for instance, in Brazil, Colombia, Philippines, Pakistan, Mexico and Indonesia - transfers to subnational governments automatically declined so that subnational spending also fell, thus reinforcing the economic downturn. Because subnational governments are usually responsible for providing (labor-intensive) essential services, in most countries the pressure to offset their budget loss was intense. In the case of Mexico, for example, the federal government borrowed to create a stabilization fund to shore up some of the decline in transfers. In other countries, subnational governments protected their expenditure budgets by lobbying for discretionary grants, increasing local taxes and covering deficits with varying forms of short-term borrowing. In still others, local and regional governments were forced to bite the bullet and cut their expenditures significantly. 41

Even without a worldwide recession, central governments in many developing countries have trouble controlling the size of the annual deficit. The conventional approach to resolving this problem is some combination of an increase in central taxes and a cut in central expenditures. The combination that is finally chosen depends to some degree on how intergovernmental fiscal transfers work. If part of any central tax increase automatically flows out to subnational governments in the form of intergovernmental transfers, taxes need to be increased by even more to meet any central government deficit reduction target. On the other hand, if transfers are discretionary, cutting them is often chosen as a convenient way to pass on part (or all) of the cost of deficit reduction to the subnational governments. In this 
and other ways, decentralized countries face different and sometimes more difficult problems in designing and implementing stabilization policy than do more centralized countries.

\section{Subnational Government Borrowing}

A related problem that has been much discussed is the danger of default on debt by state and local governments, and subsequent bailout by the central government. When Brazilian state governments defaulted on debt in the early 1990s, it precipitated a national fiscal crisis and forced central government intervention (Ter-Minassian and Craig, 1997; Rodden, 2003; Dillinger et al., 2003). The states correctly perceived that they faced a 'soft' budget constraint - a concept discussed further in Chapter 5 - because they would be bailed out by the center. As a result, many over-borrowed and overspent relative to their revenue inflow, and then had to be rescued by the central government. Subsequently, a fiscal responsibility law was enacted to impose discipline on the states - as well as on the federal government - to prevent such problems in the future (de Mello, 2007; Rezende, 2007). Somewhat similarly, in Argentina provincial government borrowing from banks run by the provinces went unchecked in the 1990s. By the time the situation led to a similar bailout by the central government in 2000 , many provinces had committed more than 60 percent of their intergovernmental transfers as repayment guarantees (Webb, 2004; Braun and Webb, 2012).

Examples like this do not mean that subnational government borrowing is inherently bad. In fact, as we discuss in Chapter 4, such borrowing is often both desirable and efficient when it comes to financing investment in long-lived infrastructure. The problems mentioned above arise because regional and local governments are too often not held to a hard budget constraint by the market (which believes they will be bailed out by the central government) and not subject to a proper regulatory framework that ensures they can repay the loans they secure without being bailed out. In the end, therefore, the real problem is not so much that subnational governments are prone to borrow more than they should, but that the central government has not placed sufficiently credible controls in place to ensure that they will not. The central government creates a 'moral hazard' by standing ready to provide a bailout for local governments that over-borrow. Alas, like many people, few governments seem able to withstand temptation long when there are no consequences from sinning.

The simplest way to avoid such problems, though not the best, is to prevent subnational governments from borrowing at all. In Egypt, for example, 98 percent of government revenues are raised by the central 
government, which also makes most government expenditures ( 86 percent) (Smoke, 2013) In such circumstances, it is simple to centralize all borrowing, with the proceeds being spent directly by the central government or assigned to regions as capital grants. A less centralized, and arguably better approach is to permit subnational governments to borrow through a centralized agency. The most decentralized approach is to establish a clear central regulatory framework and to require all subnational borrowing to follow the rules. ${ }^{42}$ We return to this issue in later chapters.

\section{Efficiency}

Fiscal decentralization will lead to a different package of public services than will centralization. For example, while national investment spending is more likely to focus on infrastructure with both regional and national benefits such as large irrigation projects, national (interstate) roads and power, local governments are likely to focus more on programs that benefit their constituency, which may bias them toward social development projects. But, as we discuss in Chapter 4, subnational governments are responsible also for much growth-facilitating investment, for example, on transportation networks. Some subnational 'consumption' expenditure on education or health may also do more for growth than such national 'investment' expenditures as the construction of a new presidential palace or a highway to the favored summer resort of political leaders.

Central officials often express concerns about the capability of regional and local officials to plan and execute projects. Sometimes these concerns are warranted. If this is a problem, however, the best response is to do more to build capacity at the subnational level, not for the central government to take over everything. Similarly, while it is clearly correct to say that local governments have little incentive to take spatial externalities into account, the answer is not for the central government to eliminate local decision-making power; rather, as we discuss in Chapter 7, it is to design a transfer system to provide the needed incentive by ensuring that those who make local decisions face 'prices' that motivate them to take such externalities into account. The larger the role regional and local governments play in establishing and maintaining growth-facilitating physical and human infrastructure, the more important the central government's role as coordinator and facilitator of such investment becomes. Decentralization does not mean that the central government's role in development policy necessarily becomes smaller. But it does mean that the nature of that role changes substantially from doing things itself to ensuring that others have the incentives and ability to do them, and that they in fact do so - 'steering' not 'rowing' as Osborne and Gaebler (1992) put it. ${ }^{43}$ 
Concerns about local capacity are by no means confined to investment projects. Anyone who examines decentralization in any developing country quickly learns that the major central government reservation is often that the capacity of local governments to deliver services is too weak to risk devolving responsibility for important services to them. Sometimes such concerns may be put forward primarily in an attempt to maintain control and power at the central level. Sometimes, however, such concerns are valid and well advised, often particularly in the poorer (and most needy) regions of a country. This is one reason experts often suggest that any decentralization should be asymmetric, assigning expenditure responsibilities (and revenue powers) to subnational governments as and when they are able to carry them out effectively. ${ }^{44}$ We discuss later why such advice seems seldom to be well received.

The combination of economies of scale, the superior 'know-how' of central agencies and the commonly observed tendency to deliver services in the same way in all parts of a country is often taken to mean that centralized provision will deliver services at lower unit costs than decentralized provision. This argument is not always correct. There are often important diseconomies of scale. Some public services require local factor inputs (for example, land and labor) that can best be managed locally, and the delivery of many services requires familiarity with the local area to deliver the service in an efficient way. ${ }^{45}$ Examples include refuse collection, traffic control and probably primary education. Other services such as secondary education may perhaps be better provided within an area large enough to allow scale economies to be captured but small enough for local voters to have some significant say in how such services should be delivered and financed. A more decentralized structure may also mean more duplication of services and more government employment.

A large part of the problem is often unskilled human capital. In Luanda, Angola's capital, for instance, as recently as the 1980s, 29 percent of civil servants had only primary school education, and only 7 percent had a degree from an institution of higher learning, with the situation being presumably even worse outside the capital city (Management Systems International, 2008). Better-qualified people are more likely to be drawn to the central government, where their opportunity for advancement appears to be greatest and they are paid more. Moreover, when central officials have been doing a job for a long time, whether it is collecting taxes or delivering specific services, they are presumably further up the learning curve than their counterparts at lower levels of government. And, of course, they are also unlikely to be willing to give up their jobs or to transfer to lower levels of government.

Stories of service delivery failure by newly empowered local governments 
are not difficult to find. For example, Uganda embarked on an ambitious program of fiscal decentralization in the 1990s without adequately preparing local governments to assume their new responsibilities. The resulting failures in financial management and service delivery significantly weakened the case for further fiscal decentralization (Steffensen, 2006; Smoke et al., 2010). In Sierra Leone, local councils were given authority to recruit their own technical/professional staff, following guidelines set up by the Local Government Service Commission. However, the skill level of newly recruited staff was much below that of the deconcentrated central officials who previously had the posts in question because more qualified individuals could not be attracted by local governments with low rates of remuneration and uncertainties about career advancement duties (World Bank, 2009). On the other hand, as Jibao and Prichard (2015) show, some cities in Sierra Leone managed to do much better than others despite operating in the same environment. Generalizations about local government performance even in very poor countries always need to be viewed in the context of the underlying situation.

In countries with stronger subnational taxes and considerably more experience with local administration, such as Brazil, some states reportedly have tax administrations at least as good as the central administration, and subnational governments have a comparative advantage in administering most subnational taxes (Pinhanez, 2008). In others, for example Colombia and South Africa, the level and quality of administration in such large cities as Bogotá and Cape Town is good, and these governments have had fewer problems in attracting skilled employees. Moreover, local administrative capacity can sometimes be quickly improved. In Indonesia, for example, a major decentralization effort in 2001 was largely successful because some 2 million central government employees who were already involved in providing the services in the local area on behalf of the line ministries were transferred to the jurisdiction of local governments. The result was that the quality and cost of these public services - now delivered under a decentralized system - did not suffer greatly (Hofman and Kaiser, 2004). As this experience suggests, one route to successful decentralization may sometimes be to begin with deconcentration - provided that those already experienced in running the services in question are kept in place at least to some extent (Bahl and Martinez-Vazquez, 2006a).

Another route is to identify areas where subnational governments have some comparative advantage in principle, and then to begin by devolving greater responsibilities first to those who are demonstrably most competent to deliver them properly. As mentioned earlier, this approach will initially produce an asymmetric system in which the more advanced (and usually more urban) areas will have more expenditure and revenue 
raising responsibility than others. Whether for this reason or because there are strong traditional, constitutional or political requirements to treat all regions or localities equally, asymmetry may prove unacceptable, even though equal treatment may produce very unequal results when applied uniformly to the usual local government mix of large metropolitan governments, smaller cities and towns, and villages and settlements varying widely in terms of poverty and remoteness. For many countries, and many parts of many countries, the ideal approach may not be either complete centralization or all-out decentralization, but some form of partial decentralization. Chapter 8 considers one important aspect of this question - the financing of large cities - in more depth.

Yet another approach to the local capacity issue may be to accompany better training and preparation for local officials with a better central information system about what is really going on out there. 'Big data,' carefully used, can provide valuable information. It can serve not only as a basis for monitoring (and to some extent influencing) those decentralized activities where financing is still mainly national but also as a better starting point for the development and execution of decentralization policy in general. ${ }^{46}$

The capacity of subnational governments to deliver services has matured significantly in recent years in many low- and especially middle-income countries. More affordable technology, improved education of more skilled staff and better employment opportunities have all contributed to this improvement. Experts such as accountants, engineers and valuers are usually in short supply, and management systems in many local governments remain weak. But, particularly in the larger urban areas of many developing countries, local governments are much better than they were a few decades ago, which is one reason that decentralization is more likely to be effective and efficient in big cities (see Chapter 8).

However, even countries where such improvements have been slow to develop have moved ahead with decentralization. In India, for example where an important constitutional amendment in 1992 for the first time gave local governments an important role in the federal system (Rao and Singh, 2006; Bahl et al., 2010a) - there is still much to be done before that role becomes reality (Ahluwalia et al., 2014). In Brazil, where local governments have had an important constitutional role since 1988, their budgetary positions have been strengthened (Rezende, 2007), although again much more remains to be done (Ter-Minassian, 2015).

Even when, as in the cases just mentioned, subnational governments have an important role in service delivery, their capacities to assume these responsibilities may be very different. For the larger urban governments and for regional governments the economic case for more fiscal responsibility is usually clear. For smaller and more rural local govern- 
ments, however, prudence may often suggest a more modest approach with respect to transferring responsibility for service delivery (perhaps allowing smaller local governments to take on more when they can do so effectively). As we discuss in more detail in later chapters, an asymmetric approach to decentralizing responsibility for public service delivery is generally advisable - though perhaps not always politically feasible.

\section{Corruption}

The early students of fiscal decentralization were concerned that it may lead to a greater rate of corruption. Prud'homme (1995) and Tanzi (1996), for example, suggest that the 'closeness' between elected local politicians and the local political power structure breeds corruption. It is not difficult to think of other reasons why decentralization might lead to more corruption. For example, decentralization often means less and weaker central monitoring and control, and hence more opportunity to steal. Increased direct contacts between the public and lower-paid local public officials may lead to more bribery and corruption. Local citizens may have little experience or knowledge of how to monitor and discipline local politicians and officials.

Such problems may perhaps be most serious with respect to infrastructure where there is more latitude for fraud, bribery, embezzlement and patronage - although, as usual when it comes to inherently unrecorded activities like corruption, the evidence is far from clear. ${ }^{47}$ For example, although Mauro (1995) argued that corruption is more likely to raise infrastructure spending (higher unit costs), Tanzi and Davoodi (1997) argued that corruption will lower infrastructure spending (fewer projects will be undertaken). The empirical evidence that corruption costs are greater under a more decentralized system is neither clear nor convincing (Shah, 2016). Estimates are inherently difficult because data are scarce and because the conceptual model is not easily worked out. ${ }^{48}$ The common perception of high local corruption may perhaps reflect its greater visibility. Corruption at the central level may be much greater though less obvious. Even if smaller in scale, however, local corruption may often be damaging to building trust in government.

At whatever level it occurs, as Estache (2006) notes, corruption is a symptom of a deeper underlying problem - the lack of political commitment and accountability. As Bardhan and Mookherjee (2000) show, simply financing local infrastructure through user fees (as discussed further in Chapters 5 and 8) rather than local taxes or intergovernmental transfers will reduce corruption, no matter how poorly local democracy works. Of course, when politicians and officials gain much of their income from exploiting their monopoly power to grant licenses, bestow contracts or 
provide services, they are unlikely to give up such power (and income) without a fight. It is seldom easy to design or implement feasible solutions to long-established corruption networks short of a fundamental revision of the relationship between state and citizens - even though doing so is itself likely to be an essential element of any such revised relationship.

\section{CONCLUSIONS}

Fiscal decentralization is not a cure-all for governance and service delivery problems. In theory it can help, and some countries have turned this theory into practice with good results. But most low- and middle-income countries are unlikely to be able to realize these potential benefits immediately and fully, and even those that could do so may not be able to muster and sustain the necessary political will. It is thus not surprising that despite the burst of literature and discussion about fiscal decentralization in recent decades, there is not all that much evidence of effective fiscal decentralization on the ground in low- and middle-income countries. Based on the International Monetary Fund's (IMF's) Government Finance Statistics - the only comparable (though limited) data source available - the subnational government share of public expenditures in developing countries has not experienced a significant uptick over the last two decades. ${ }^{49}$ There may have been a great deal of progress with fiscal decentralization in more subtle ways that would not necessarily show up in the subnational government expenditure share for example, by removing central mandates on expenditures, replacing conditional with unconditional grants, and more local cost recovery from user charges - but we are not aware of any systematic evidence to this effect.

The strengthening of subnational government finance may perhaps be likened to buying more of a luxury good. Richer countries find fiscal decentralization more affordable because their economies are more stable, regional wealth disparities are less pronounced, the infrastructure is mostly in place, and the administrative capacity of their subnational governments is stronger. The big battles about which level of government will do what and how it will all be financed are in the past. The story is very different in most low- and middle-income countries where the political costs of decentralizing are sometimes considerably higher. Central bureaucracies are usually firmly entrenched and difficult to move. Even at the local level, the tradition of central control often seems inviolate. In most countries, local voters - those who in principle would benefit most - are either impotent or do not understand that decentralization can be a desirable and sustainable component of a sound development policy.

It is not easy to evaluate how successful decentralization has been - 
however 'success' is measured - in any country, let alone to evaluate that success in statistical terms. Data deficiencies and the complexity of the issues often make comparative statistical studies less informative than careful country case studies, although one must also be cautious in drawing generalizations from even the best-structured comparative case studies. One lesson that does emerge clearly from most case studies, however, is that the design of decentralization efforts has often been flawed, that implementation is complicated, and that it almost always takes a long time for any impacts to show up clearly enough to be evaluated in any meaningful way. Nonetheless, fiscal decentralization, if done right, can be an important component of a sustainable development strategy in many countries. Although countries usually embark on decentralization for essentially political reasons, they do so in better and worse ways from a developmental perspective. Our aim in this book is to provide some guidance to those involved in such activities by reviewing the evidence to date and considering in some detail what theory and experience suggest are the best ways to go when it comes to the never-ending task of adjusting governance structures to changing circumstances in ways that best satisfy what people want their governments to do.

Summing up, decentralization as we consider it here is essentially a way of ensuring that people get what they want from government. Done correctly, it can be beneficial. But it is neither easy nor cheap to do in most circumstances, so it is worth spending considerable time and effort in working out exactly what it is you want to do, why you want to do it, and how you can best do it. It is also important to set up the appropriate institutional arrangements within which decentralization has a reasonable chance to be successful, and to do this well before engaging in the process - for it is a process, and an ongoing and evolving one at that. Given the complexity of the exercise, it is not surprising that few developing countries have moved very far in the direction of the kind of decentralization discussed here. However, many have begun to move down this path, and it is important that the considerable efforts already made and in train are not wasted. Decentralization can be rewarding from a developmental perspective in many ways. But doing it right requires deeper and more sustained efforts than seems generally to have been realized. It is not surprising that to date experience in many countries has not been all that good. Each country at each point in time is a unique case. But all face some common problems, and there are usually a variety of ways - often already tried elsewhere - in which they can attempt to deal with these problems. Our hope is that this book may perhaps help some to avoid common pitfalls and offer some clues about how countries may do better in decentralizing in the specific circumstances they face. 


\section{NOTES}

1. In addition to many good regional and country studies, the more general studies include Bahl and Linn (1992), Dillinger (1994), Tanzi (1996), Ter-Minassian (1997), Litvak et al. (1998), Bird and Vaillancourt (1998), Bardhan and Mookherhee (2006), MartinezVazquez et al. (2006b), Smoke et al. (2006), Boadway and Shah (2009), Eaton et al. (2010) and Bahl et al. (2013).

2. This wording embodies two strong assumptions. The first is that good governments are those that do their best to fulfill the wishes of the people whom they govern - an unspoken assumption in most analysis of public sector economics. The second is that the principal way we know to ensure that governments are accountable to their people at least periodically and to some extent - is through democratic elections. The first assumption is of course more a wish than an expectation in many countries. The second is contrary to the reality found in many developing countries. We return to both points later in the book.

3. In federal countries, such as the United States and Canada or Brazil and India, the division of spending and taxing powers between levels of governments is specified to varying degrees of detail in the constitution, and not easily subject to legislative change. We discuss some issues that may arise in federal countries as a result of such constitutional requirements, but generally assume here that we are dealing with countries in which the extent of decentralization is largely a matter for the central government to decide.

4. To make things simpler in this book, we often refer to 'local governments' instead of using such more accurate but cumbersome expressions as 'subnational' or 'sub-central' or 'regional and local' governments. When relevant to our story - for instance, in federal countries in which some subnational governments have different constitutional powers (for example, regional governments in some countries may have essentially the power of a 'central' government with respect to the structure and powers of lower levels of government within their territory) - we distinguish between the different levels of 'local' government. In this book, however, we do not treat the special case of federal countries in detail: on this, see Slack and Chattopadhyay (2009), Bizioli and Sacchetto (2011), and Slack and Chattopadhyay (2013). For further discussion of the difference between federal finance and fiscal federalism, see Bird and Chen (1998).

5. In a well-documented and reasoned book, Treisman (2007) argues that no one can yet make solid generalizations about decentralization. We reach much the same conclusion in our review of the empirical evidence in Chapter 2. As Treisman concludes, however, decentralization can be good policy if it is done 'right' - that is, right in terms of the prevailing objectives, conditions and constraints - and if the gains are worth the costs inevitably involved in restructuring institutions. We agree, and see this book as an attempt to provide clearer guidance to would-be decentralizers seeking to do the best they can in the conditions they face.

6. Of course, deconcentration does not always work so smoothly. At one time in the Philippines, for example, nurses at some hospitals were employed by three different levels of government - central, provincial and local, with each category receiving different wages for essentially the same work. Much the same was true with respect to teachers in Colombia in the early 1990s (World Bank, 1996), although in this case the rationale was less orders from above than attempts from below to offset the effects of higher-level controls. Such situations are more likely to yield unhappy providers than good services.

7. See Spahn (2015) for an interesting discussion of such 'contract federalism.' For discussion of several interesting examples of intergovernmental contracting in Colombia, see World Bank (1996).

8. As Congleton $(2015$, p. 139) says, with asymmetrical information "decentralization is not an exogenous feature ... but rather an endogenous result of ongoing negotiations over the assignment of central and local authority." For a good appraisal of this issue 
in the general context of federal arrangements, see Bednar (2009), and for an interesting early treatment, see Cremer et al. (1995).

9. For an example, see World Bank (1996). A particularly egregious instance in Colombia occurred when the central government mandated that every local government must provide free telephone access to the central government so that residents could register complaints about their local government. In some remote rural areas the cost of complying with this mandate exceeded the entire municipal budget.

10. While fiscal decentralization is about the devolution of budget autonomy, the extent of such autonomy and how it works are obviously related to the number, size and diversity of local governments operating in a country, irrespective of their fiscal powers, as is discussed with some care in Lago-Peñas and Martinez-Vazquez (2013).

11. The dollar amount of support is not easily estimated because it requires prorating loan amounts between the decentralization component and other targets of support, allocating general overhead spending to decentralization, and even defining what is or is not a decentralization project. For example, should an urban transportation project that would empower a local government to deliver bus services be classified as a 'decentralization' project? For a more recent study covering a broader range of donor assistance to larger urban areas, see Kharas and Linn (2013).

12. The linkage between separatist movements and fiscal decentralization is discussed later in this chapter, and in more detail in Bird and Ebel (2007) and Vaillancourt and Bird (2016).

13. We take up the discussion of the relationship between decentralization and growth in Chapter 2.

14. As noted earlier, Russia has seen many changes, first towards decentralization then back to a more centralized structure: for glimpses of this changing picture, see, for example, Treisman (1999) and Martinez-Vazquez et al. (2008).

15. For example, for three months no provincial monthly financial reports, which are supposed to be reviewed by the central ministry, were received. On investigation, it turned out that the reports had arrived but that procedure required their receipt had to be officially logged before they passed to the review section. This did not happen because the official responsible for logging incoming reports was on leave and, on his return, did not bother to catch up with the backlog. No one noticed.

16. Sometimes in some countries the only way a central official could visit certain regions was with a military escort. It is not surprising that at times the only contact such regions had with the central government was when someone (and their escort) came to collect taxes. Regional conflict is sometimes handled quite differently. During Colombia's prolonged armed conflict, for example, some municipalities under rebel control regularly received most of the national transfers to which they were legally entitled.

17. China has 151 prefectures and 185 prefecture-level cities; 1,903 counties and 279 county-level cities; and 56,000 townships, towns and city districts.

18. India has 3,609 urban local bodies and, in rural areas, 474 zilla parishads, 5,906 panchayats samithis and 227,698 gram panchayats.

19. For a review of the very different ways and extent to which decentralization occurred in different parts of Soviet-controlled central and eastern Europe after the late 1980s, see Bird et al. (1995).

20. One well-documented example is that of Madhya Pradesh state in India, where teacherabsentee rates were much more effectively monitored by local communities than by the state government (McCarten and Vyasulu, 2004).

21. http://www.citymayors.com/government/mayors-americas.html (consulted February 2, 2016).

22. Even when elections exist and are free from corruption, how accurately and effectively they reflect local preferences depends on many context-specific factors, including: the nature and role of political parties; the structure of the electoral system; the rules determining eligibility to vote; and the extent and nature of voter participation. The extensive literature exploring these and other problems in establishing even an imperfectly functioning democratic electoral system cannot be further explored here, however. 
23. For a limited study at the village level that briefly explores this issue, see Bird et al. (2011).

24. For some interesting takes on how government structure can get in the way of accountability, see Eaton et al. (2010).

25. For an interesting account of Brazil's experience with 'open budgets' as well as other approaches to greater budgetary transparency, see Khagram et al. (2013).

26. The role of the media in informing people about the activities of local government is also important in the accountability process. While this issue seems to have been relatively little studied, one study of the local editions of three widely circulated newspapers in rural Kerala province (India) found that the space allocated to news about local government was only a little over 3.5 percent of the total space available (Sethi, 2005).

27. See, for example, the interesting discussions of rural political unrest in China in Bernstein and Lü (2003) and O'Brien and $\operatorname{Li}(2006)$.

28. Tax data are from various sources and various dates (Bird, 2012).

29. Even this is probably an overstatement because many countries do not report the finances of their local governments, and because some of the "taxes' attributed to subnational governments are really, as we discuss in the next chapter, intergovernmental transfers in disguise.

30. Bahl and Cyan (2011) found some evidence of such 'crowding out' in Organisation for Economic Co-operation and Development (OECD) countries but not in developing countries.

31. As we discuss further in Chapter 5, such arguments often confuse economic and administrative efficiency (Bird, 2015).

32. The Sri Lankan case is not discussed further in this book. Moore (2017) provides an interesting look at recent trends in public finance in Sri Lanka but, interestingly, does not even mention the issue of decentralization.

33. For further discussion, see Bird and Ebel (2007) and Vaillancourt and Bird (2016).

34. See, for example, the seminal studies in Brautigam et al. (2008), and especially the recent detailed exploration of Ethiopia, Ghana and Kenya in Prichard (2015).

35. One of us once protested some arbitrary decisions made by a state-appointed tourist 'guide' in the Soviet Union, only to be quickly told by fellow tourists (all from Sovietdominated countries) that "the only safe thing to do is to keep your head down and your mouth shut." Alas, this is still sound advice for both visitors and residents in all too many countries around the world.

36. There is some evidence from developed countries that smaller sized governments lead to increased political involvement (Pommerhene and Schneider, 1983). In early surveys in the US, respondents consistently identified local government as the level of government in which they have the greatest trust (ACIR, 1994). A similar finding emerged from a survey in Colombia (Acosta and Bird, 2005).

37. See the case studies in Bird and Ebel (2007) and Vaillancourt and Bird (2016).

38. However a few years later, when Russia again became a much more centralized system, these treaties were recalled (Martinez-Vazquez et al., 2006c).

39. Interestingly, sometimes national governments have deliberately continued to pay transfers to regions under rebel control both to keep lines of communication open and to, as it were, pay Danegeld (a term from early British history, when bribes were paid to persuade Danish invaders to refrain from armed assault).

40. More detailed discussion of this subject may be found in Bahl and Linn (1992), Prud'homme (1995), Ter-Minassian (1997), Tanzi (1996) and Spahn (1997); an excellent recent overview is Boadway and Shah (2009). For an empirical analysis, see Wibbels (2000).

41. For a set of interesting case studies, see Eccleston and Krever (2017).

42. For a good discussion of regulatory frameworks for subnational government borrowing, see Liu and Waibel (2010). See also Van Ryneveld (2006).

43. For an interesting application to local government in two OECD countries, see Barlow and Robler (1996). 
44. For extensive discussion of such 'asymmetric federalism,' see Bird and Ebel (2007) and Congleton (2015). As Acosta and Bird (2005) discuss, Colombia seems to have been fairly successful in decentralizing most education and health services to the regional level asymmetrically, with the central ministries remaining more directly involved in the less-advanced regions. Colombia's experience with its earlier decentralization of most responsibilities for most local water services to municipal governments also appears to have been generally successful, though again significantly more so in some parts of the country than in others (Granados Vergara et al., 2008).

45. Even in industrialized countries, there is evidence that the 'optimal' size delivery unit for many local public services is in the range of $20,000-40,000$ people: see the studies summarized in Slack and Bird (2012). This issue is discussed further in Chapter 3.

46. Indonesia and South Africa are two examples of countries that significantly updated their database on subnational government finances in the aftermath of fiscal decentralization. At the individual level, India's introduction of a national biometric identification system obviously has potentially major implications for improving service delivery at the local as well as the national level.

47. The fear that ramping up local infrastructure spending is likely to increase corruption is by no means confined to developing countries. In Canada, for example, when a major federal program was launched in 2016 to spend billions on local infrastructure across the country the federal Competition Bureau felt it necessary to double its training workshops for public procurement officers "on how to identify and prevent collusion and corruption" (Curry 2016).

48. For reviews of this literature, see Martinez-Vazquez et al. (2007), Boadway and Shah (2009) and Shah (2016).

49. We measure decentralization here as the subnational government share of total government expenditure in the country - that is, subnational government expenditures in the numerator, and total central plus subnational government expenditures in the denominator. The limited utility of this measure is discussed further in the next chapter. 